\title{
An Empirical Study of Internet Use in Saudian's Small and Mediums Enterprises
}

\author{
Dr. Mohammad. J. Adaileh \\ Qassim University, Saudi Arabia \\ E-mail: mohd28112001@yahoo.com
}

Received: October 20, 2011

Accepted: November 22, $2011 \quad$ Published: March 1, 2012

doi:10.5539/ass.v8n3p169

URL: http://dx.doi.org/10.5539/ass.v8n3p169

\begin{abstract}
Employing the Internet as a tool can help address some of the critical issues affecting SMEs in Kingdom of Saudia Arabia, such as increased global competition, increased consumer demand for quality, increased partnerships between large/intermediate and small businesses, rapidly changing market environment, growing need for immediate access to current business information from a variety of sources, The purpose of this study was to assess the current level of Internet usage as a business tool by SMEs that formed the basis for an earlier study, The small companies have experienced a variety of difficulties in their adoption of the Internet as a business tool, and there have been a variety of benefits realized by small companies. Lastly, they have experienced problems such as cost increases since their adoption of the Internet as a business tool.
\end{abstract}

Keywords: Small and Medium Enterprises (SMEs), Internet use, Electronic Commerce (EC), Business tools, Brochure ware, Integration

\section{Introduction}

Small and Medium Enterprises (SMEs) have been recognized as important contributors in the economy of many countries and new opportunities are opening for them in domestic and international markets. It is vital for an SME to grow in order to remain competitive in these markets (Abouzeedan, Busler, 2002). According to researchers, there is no single theory which can sufficiently explain growth of an SME but the importance and use of the Internet is becoming increasingly visible among small and medium enterprises ( Harindranath, et al, 2008 ). However, in spite of the Internet's potential, most of the firms do not view it as key to their strategies for growth. The aim of this thesis is to investigate how SMEs are using the Internet in strategies they adopt for growth ( Hussin, Noor,2005)

The World Bank's Small and Medium Enterprise (SME) Department promotes local small business growth in developing nations. As noted on the World Bank Group's website: "For an impoverished family in a developing country, establishing a small- or micro-enterprise often represents the first tentative step toward self-sufficiency. The SME sector as a whole can galvanize an entire economy, creating jobs and spurring growth. In much of the developing world, the private economy is almost entirely comprised of SMEs. In Ecuador, for example, 99 percent of all private companies have no more than 50 employees. Bottom line? SMEs are frequently the only realistic employment opportunity for millions of poor people throughout the world. "Out of the four key ways that the World Bank helps SMEs, one of them is through helping smaller enterprises obtain access to the Internet and information technology. The World Bank aims to help SMEs leverage technology and the Internet to discover market information, link up with suppliers and sell to global customers. It is surprising to find that the World Bank places so much emphasis on the Internet and information technology - so much so that it's one-fourth of their SME strategy (Kalakota,Robinson, 2001). Without a doubt, the Internet has increased the pace of globalization dramatically. And it has become an indispensable tool for businesses in the developed world (Kleindl, 2000). But are most SMEs in third world countries really ready to do business using the Internet? Or do they have more pressing needs?

It's a big mistake to think that large-scale businesses are the main driver of economic activity but rather small and medium-sized enterprises "are considered the most efficient and capable instrument to accelerate the pace of economic and social development" in both advanced and developing countries (Aljitri,et al, 2003). SMEs are attractive for other reasons, including the simplicity of their establishment and administrative structure because 
of the small amount of capital needed for initial foundation and operation (Limthongchai,Speece, 2003). Limited liability allows SMEs to exit the market with little significant impact (Pavic, et al 2007). SMEs in KSA should take advantage of the opportunities offered by electronic commerce in order to narrow the gap with developed economies, Intellectual assets and knowledge now exceed physical capital in value, uncertainty and a lack of awareness and technical skills" are preventing equal participation in the information society (Syed, et al, 2005). It is crucial for a country like KSA to "make the transition to an e-economy so as to narrow the gap between it and developed economies (Heinz, Woerter, 2007). The aim is to highlight e-commerce success stories for Saudian companies. Expansion of e-commerce is set to take off in the Arab world where Internet users are expected to triple in the next three years (Syed, et al, 2005). This movement to E-Commerce would be beneficial in the long run (Jeff, et al 2003). Companies that provide infrastructure for e-marketing such as SMS services and centralized check clearing could sell their services and products throughout the region and in the global market (Mahesha, Lawson, 2006).

Most of the researchs that has been conducted on the topic of SMEs and e-business and/or e-commerce has investigated SMEs. Although the results indicated that the great hope of the Internet for SMEs was for greater competitive advantages (Sekaran, 2003), including participation in new export sectors, streamlining of business activities, and greater effectiveness in linking with trade development partners, many SMEs have failed to adopt and exploit Internet technology either because they have not recognized its potential or because they have perceived the risk of changing their business model to use the new technology to be greater than the benefits that might be derived (Beach, 2004).

In addition, while Internet use may not produce greater potential opportunities for smaller businesses compared to larger concerns, the potential costs for small and medium sized firms with no Internet presence may be even greater (Becherer, Haynes, \& Helms, 1998). Another looming threat is that large companies can now efficiently turn their attention to smaller market niches, once the domain of SMEs that could compete by developing personalized relations with their customers, customizing their offerings, and efficiently targeting niche markets (Kleindl, 2000). Few SMEs have advanced beyond establishing a simple Web site; most do not have a Web site that involves front and back office integration (Wymer, Regan, 2005). Because most of the research in the world has focused on large companies, and there is disagreement among the few research reports that have studied SMEs, it is believed the results of this research will aid those private, public, and academic institutions charged with helping Saudian SMEs.

If SMEs in KSA are to successfully compete in an increasingly competitive and global marketplace, it is imperative that they embrace the full benefits that are available through optimized use of the Internet. This research sought to examine the current rate of Internet adoption for business solutions by SMEs in KSA through execution of a survey of a random sample of 100 manufacturers with less than 249 employees, obtained from a database of ministry of labour and ministry of commerce and chamber of commerce, and from many resources if available. Survey instrument was used. The purpose of this study was to assess the current level of Internet usage as a business tool by SMEs that formed the basis for an earlier study. Levels of involvement were established as Phase I (brochure ware), Phase II (transactions), and Phase III (integration).

Results of the research may aid governmental, academic, and other institutions in the KSA and elsewhere that are interested in the economic progress of SMEs and that are developing programs and services that match up to real needs in the marketplace. A great deal of attention is being paid to the adoption of the Internet for business solutions by SMEs because of the importance of small and medium-sized businesses to national economies. In KSA, there appears to be less support, interest, and attention paid to the use of the Internet. Recognizing the great potential of the Internet to increase gross domestic product (GDP) and to address global challenges, many governments are seeking to encourage, facilitate, and increase the adoption of e-business strategies through funded projects that focus on Internet commerce adoption, technology diffusion, virtual business networks, societal issues and other conventional e-commerce applications (Beal, 2001). In response to greater liberalization of foreign trade regulations and competition from the global markets. SMEs have been unable to significantly increase their export volume on their own. The main reason for this drawback is the lack of knowledge in the International markets (Al-Qirim, 2006). Domestics Exporters who have not build up their presence in foreign markets do not usually have neither the resources nor the capacity to carry out export promotion and development activities, which are generally expensive (Economic Planning Unit, 2001-2005, 2006-2010).

\section{Study background}

\subsection{SMEs}

Because SMEs comprise a very large part of the global economy and employ a great number of workers, their successful adoption of Internet-related capabilities is of great interest and the focus of much research, education, 
and training (Eriksson, Hultman, 2005). In Canada, for example, SMEs are responsible for $60 \%$ of economic output, generate $80 \%$ of national employment, and create $85 \%$ of all new jobs Shape the future, 2008). However, according to published research, for a variety of reasons, many of which are internal and behavior related, most SMEs have yet to fully embrace e-business capabilities with many limiting their involvement to e-mail and/or brochure ware Web sites (Levy, et al, 2005, Rola, 2002).

The Internet and the WWW have created new cost-effective means for both large and small businesses in order to increase domestic and international sales, decrease costs, enhance customer relations, and build customer loyalty. For example, according to Elder, Litan, Shutter, Varian and Janu (2002), organizations of all sizes in the United Kingdom, France, Germany, and the United States report a cumulative cost savings of $\$ 163.5$ billion and an increase in revenues of $\$ 444$ billion because of the adoption of Internet solutions. The Canadian National Railway Company, which has more than 75,000 catalog items, saved or cut $\$ 10$ million in procurement costs by replacing phone, fax, mail services, multidisciplinary committees, and labor intensive requests for proposals with Internet-based procurement systems (Subramaniam \& Talha, 2003). Small and medium enterprises (SMEs) can employ a variety of means to harness the power of the Internet, the WWW, and related technologies. Activities can range from something as simple as using the Internet for communications with customers and suppliers to a full integration that can provide for sustainable competitive advantages while providing at the same time for a low-cost entry into the global marketplace (Shape the future, 2008). Employing the Internet as a tool can help address some of the critical issues affecting SMEs, such as increased global competition, increased consumer demand for quality, increased partnerships between large/intermediate and small businesses, rapidly changing market environment, growing need for immediate access to current business information from a variety of sources, increased competition for capital, greater need to track legislation affecting small businesses, and the growing need to stay flexible (Martin, 2009). The Internet also allows for an increase in the number of vendor options available to small and mid-sized businesses that previously may have had only a small number of local procurement options. Improved cost control, shortened lead times, and faster and accurate order processing can also be enhanced from Internet usage (Becherer, Haynes, and Helms; Benjamin and Wigand, 1995; Hapgood, 1997, Piergiuseppe \& Giuseppina, 2005, Porter, 2001).

According to Kalakota and Robinson (2001), the first phase of e-commerce (1994-1997) was represented by Web sites, which were brochure ware that replaced existing corporate brochures and other printed material. In the second phase (1997-2000), the focus was on transactions, while the third phase (2000 and later), defined as e business, included front office applications that involves buying and selling over the Internet as well as back office applications that enable a company to use the Internet to increase profitability (James,2003). Because the Internet and the WWW can help SMEs to increase domestic and international sales, decrease costs, and enhance and build greater customer service and loyalty, countries and academics the world over are interested in fostering use of the Internet as a business tool by their SMEs. However, most SMEs have yet to embrace fully e-business capabilities, with many of them limiting their involvement to brochure ware Web sites and/or e-mail (Pool et al, 2006).

\subsection{SMEs in KSA}

Companies in KSA are perceived to be advanced in their use of the Internet, with most of the research focusing on large businesses. There is little empirical evidence that SMEs in the KSA are maximizing their use of the Internet as a business tool. Results from the study of many manufacturing SMEs indicated that a majority use the Internet to provide information about the company and its products, but only a very small percentage integrate it with back office systems or allow suppliers to interact electronically with the company ( Organisation for Economic Corporation and Development, 2004). Porter, 2001 believed that one of the major impediments to the adoption of the Internet by SMEs for competitive advantage in such areas of human resources, finance, and supply chain, and moving beyond e-mail and electronic brochures, was caused by the history of the Internet being more about technology than about business strategy. Many SMEs in KSA have failed to adopt Internet technology because they do not recognize its potential or they perceive the risk of changing their business model to be greater than the potential benefits. SMEs make up 92 percent of the businesses in Saudi Arabia and employ over 80 percent of the work force according to the National US-Arab Chamber of Commerce's Tradeline. the SMEs contribution to total GDP is too low. The total share of private sector gross product in Saudi Arabia is only 33 percent, Saudi Arabia is moving in the right direction by promoting SMEs throughout the Kingdom to develop its economy further, Small and medium enterprises (SMEs) are the key to unlocking the vast potential of the Saudi Arabian economy. SMEs can provide valuable employment opportunities to a growing young population, improve productivity and help diversify the economy. SMEs have a strong footing within the Kingdom in that they currently make up $90 \%$ of all businesses, however, their contribution to GDP remains low. 
Considering the vast number of competing SME programs and initiatives throughout the Kingdom, Given the recognized challenges facing the SME sector in the Kingdom, SMEs have to adapt a new way to help entering the global markets (Gibbs, Kraemer, 2004), The purpose of this study was to assess the current level of Internet usage as a business tool by SMEs that formed the basis for an earlier study. Levels of involvement were established as Phase I (brochure ware), Phase II (transactions), and Phase III (integration). Within the current economic environment SMEs in the Kingdom face formidable challenges which limit their ability to remain competitive and maintain sustained growth. The absence of targeted and continuous support services and financing and marketing programs which meet the needs of SMEs across their development stages has led to short life spans for SMEs in the Kingdom where the average SME is only seven years old (Soliman,2003).

\section{Research Method}

This study sought to examine the extent of adoption of the Internet for business solutions by SMEs in KSA and to examine the key issues that affected the adoption. Because of the amount of extant literature available on the topic of e-business/ecommerce and SMEs, it would appear that a quantitative study is warranted for this dissertation. According to Creswell (2003), if the problem to be addressed in the research is the identification of factors that influence an outcome, testing of a theory, or understanding the best predictors of outcomes, then a quantitative approach is best. On the other hand, when a concept needs to be understood because there is little research, then a qualitative approach is better suited.

\subsection{Research Question and Hypotheses}

The following questions, null hypotheses, alternative hypotheses, and investigative questions form the basis for the research:

What is the extent of the use of the Internet as a business tool by SMEs in KSA?

Ho1: A majority of small manufacturers in SMEs use the Internet for business solutions other than having Web sites for promotional purposes.

Survey questions A1, A2, A3, A4, A5, A6, A7, A8, A9, B2, and B3 address the aforementioned investigative questions and include nominal data for analysis of how SMEs are utilizing the Internet for business solutions.

HA1. A majority of SMEs do not use the Internet for business solutions other than having Web sites for promotional purposes.

Is the establishment of a Web site by SMEs the first stage in further involvement with use of the Internet as a business tool?

Ho2: The establishment of a Web site is related to further involvement with the Internet for business solutions.

Survey questions A2, A3, A4, A6, A7, A8 and B2 address the aforementioned investigative questions and include nominal data for analysis of how SMEs began their involvement with the Internet, and what were factors in moving from Web sites to further involvement?

HA2. The establishment of a Web site is not related to further involvement with the Internet for business solutions.

What are the important drivers that motivate SMEs to implement use of the Internet as a business tool?

Ho3: There is no one factor that is more important than any other that influences SMEs in their adoption of the Internet for business solutions.

Survey questions B1 and B3 address the aforementioned investigative questions and include nominal and ordinal data for analysis of what important factors have influenced SMEs.

HA3. There is a hierarchy of factors, such as competitive, customer, and supplier pressure, that influence SMEs in their adoption of the Internet for business solutions.

What difficulties did SMEs encounter while implementing use of the Internet as a business tool?

Ho4: There were no difficulties experienced by SMEs in their adoption of the Internet for business solutions.

Survey question B4 addresses the aforementioned investigative questions and include ordinal data for analysis of what, if any, difficulties have been experienced by SMEs in their use of the Internet as a business tool.

HA4. SMEs have experienced difficulties, such as the cost of hardware and software, in their adoption of the Internet for business solutions.

What are the benefits that have accrued for those SMEs that have adopted use of the Internet as a business tool? 
Ho5: SMEs who use the Internet for business solutions have realized few benefits.

Survey question B5 addresses the aforementioned investigative questions and includes nominal and ordinal data for analysis of what, if any, benefits have accrued to those SMEs who have adopted use of the Internet as a business tool.

HA5. Benefits, perceived and real, such as an increase in sales, decrease in costs, and improved efficiencies, have been realized by SMEs who have adopted use of the Internet as a business tool.

What problems, such as cost increases, reductions in flexibility, security, and operational efficiencies, have SMEs encountered after implementing use of the Internet as a business tool?

Ho6: There have been no problems, such as cost increases, reductions in flexibility, security, and operational efficiencies, experienced by SMEs since their adoption of the Internet for business solutions.

Survey question B6 addresses the aforementioned investigative questions and includes ordinal data for analysis of what problems have been encountered by SMEs who have adopted the Internet for business solutions. Section C's questions on the survey instrument provide details on respondent organizational profiles (business size, type of Internet access, etc.).

HA6. SMEs have experienced problems such as, cost increases, reductions in flexibility, and duplication of business processes following their implementation of an Internet strategy.

\subsection{The Sample}

Classification of SME varies by country, but in relative terms (to GDP), opportunities \& challenges are about the same Classification criteria: \# of workers, fixed assets, turnover (in region, often use \# workers), SMEs in dominate developing countries: Egypt ( $98 \%$ of firms, $80 \%$ of GDP are SMEs $<100$ workers), KSA (99\% are SME $<50$ workers), Lebanon ( $~ 95 \%$ of firms $<50$ workers), Morocco (SMEs are $<250$ workers), ...But SMEs faces numerous challenges and market failures, which necessitate measures and policies to ensure their sustainable growth.

A random sample from labour ministry and ministry of manufacturing and commerce database in KSA of small and medium manufacturers with less than 50 employees was surveyed. Manufacturers were chosen because the sector is perceived as being advanced in its use of information technologies and because SMEs make up over $92 \%$ of all manufacturers. The 100 company names were selected randomly from an alphabetized list.

\subsection{The Survey Instrument}

A survey instrument was developed by Robert MacGregor and Lejla Vrazalic, School of Economics and Information Systems, University of Wollongong, Australia, for a Comparative Study of SMEs in Wollongong (Australia) and Karlstad (Sweden), was used for collecting the data. It was modified to reflect Saudian's business realities. It was also field tested before being used. MacGregor and Vrazalic (2004) examined the key issues that affect E commerce adoption and use in SMEs by comparing E-commerce adoption rates between 2 similar regional centers in Wollongong, Australia, and Karlstad, Sweden. Both countries have a large number of small businesses located in regional areas, the governments of both countries are keen on promoting e-commerce adoption by small businesses in these areas, and both countries are classified by the World Bank Group as high income nations and members of the Organization for Economic Co-operation and Development (OECD). Easy access to the small businesses in regional areas of the 2 countries was also a major contributing factor. The survey questions were based on previous research studies, and the SMEs were asked about their business and characteristics (size, age, business sector, market focus, level of IT skills) as well as their adoption and use of the Internet as a business tool.

To assess reliability and validity of the survey instrument, the research process included a test of the survey instrument by five experts in the field. To assess content, or "face" validity, the field test was conducted by first having five experts complete the survey to determine if the factors selected for the study were relevant to the use of the Internet as a business tool by small manufacturers. Comments and suggestions provided by experts were considered valuable and useful for improving the instrument for use in the main study. The data were manually entered using SPSS software. Data entry errors were minimized through validity and range checking, with supported skip patterns. It was anticipated that variables would be recoded, with new ones being created after the data collection was finished. 


\subsection{Data Collection Method}

Survey was conducted by personal interviews, and expanded geographic coverage, and by e-mail. To insure a high response rate, a personalized mailing, we use an introduction and announcement of the survey, promise of confidentiality of the data provided, detailed instructions, a powerful statement that indicated why the survey was important to the researcher, and an explanation about what they would get from participating (copy of the results).

\section{Data Analysis}

Using SPSS, The original tolerance margin of error of estimates $\pm 6 \%$ at the $95 \%$ confidence level, based on a result of 123 completed surveys, was adjusted because only 100 surveys were completed. The method of statistical analysis used in research to analyze data is usually determined by the way in which data are expressed; therefore, for this survey, descriptive statistics were used to examine correlations, means, standard deviations, and reveal the distribution of the data in each variable. Nominal variables in the study separated data into categories and count frequencies while ordinal order variables ranked data in terms of degree, and non-parametric measures of association were used to assess the strength of relations. In addition, because likert scales and ratios were also used in the study, a parametric test, such as a t-test or ANOVA, which makes a single, overall decision to determine if a significant difference is was present among three or more sample means, was used to test the stated hypotheses. Frequency distributions inspected the range of responses and their repeated occurrence, arraying the data from highest to lowest values with counts and percentages.

\subsection{Descriptive Analysis and Findings}

The purpose of this study was to assess the current state of adoption of the Internet as a business tool by SMEs who formed the basis of study. This study gathered information from 100 Presidents, CEOs, or Owners of SMEs. The purpose of descriptive analysis was to provide a structured depiction of the characteristics of a data set. The following summary presents descriptive statistics to quantify the characteristics of the sample:

\section{Research Question 1}

What is the extent of use of the Internet as a business tool by SMEs?

Table (1) shows the Frequency for extent use of internet. Survey question A1 asked respondents if they use the Internet in the business activities, question A6 asked if their organization had a Web site on the Internet, and question A8a through A8m sought to uncover the extent of their use of their Web sites. Eighty-seven of the 100 (87\%) respondents who answered the question reported using the Internet in the business activities of their organizations and $71.7 \%$ (71 out of the 99 respondents) reported having a Web site. A majority (69 of the 77 who responded to questions about Web site capabilities) use it to provide information about their business (89.6\%), 71 out of 77 provide information about the company's products and services (92.2\%); 68 out of 77 provide the company contact information (88.3\%), 64 out of 77 provide an e-mail link (83.1\%), and 49 out of 77 provided an online form for customers to contact the organization and/or make inquiries $(63.6 \%)$.

Less than $30 \%$ (23 out of 77 ) provide an online form for supplier inquiries, and only $22 \%$ (17 out of 77 ) provide an online form for ordering products/services which must be faxed or mailed. Subsequent responses to questions relating to online $\mathrm{Web}$ transactions indicated even less involvement with the Internet. Only $3.9 \%$ (3 out of 77 respondents) provide a non-secure form for ordering products/services online, 18.2\% (14 out of 77 respondents) report the provision of a secure form for ordering products/services online, less than $6.5 \%$ (5 out of 77 respondents) provide for an online system that allows customers to browse and order products/services but does not handle payments, and only $11.7 \%$ (9 out of 77 respondents) have an integrated online transaction system which allows customers to browse and order products/services while purchasing and paying for them using a credit card or some other form of electronic payment. When queried about further integration which would include both internal and external activities/processes, only $10.4 \%$ (8 out of 77 respondents) reported having a system that allows customers to track the status of their order, and $2.6 \%$ ( 2 out of 77 respondents) reported having a fully integrate business system that includes both front office applications (such as selling activities) and back office applications (such as purchasing and procurement).

Based on the description provided by Kalakota and Robinson (2001), it was reasonable to assess the level of respondent Web site involvement by establishing the following categories: Phase I, or brochure ware, included survey questions A8a through A8g because they focus on one way communication with external audiences, (see table:2) Phase II, or transactions, included survey questions Ah through Ak because they involved online transactions; and Phase III, or integration included survey questions $\mathrm{Al}$ and Am, which queried about level of integration. If one point is awarded for each one of the 13 categories for the Web site involvement described in 
survey questions A8a through A8m, Phase I would reflect a total possibility of seven points, Phase II a total of four points, and Phase III a total of two points, for a total of 13 points reflecting the greatest amount of involvement with use of the Internet as business tool.(see table no: 3). No respondent out of 77 respondents received 13 points, and one received 12 points; therefore, $89.7 \%$ ( 76 out of 77 respondents) have not achieved any level of integration (Phase III). For Phase II, representing transactions, one received 11 points, five received nine points, and four received eight points, representing just $14.3 \%$ of respondents. Nearly $86 \%$ of respondents achieved a score of seven or less, indicating involvement with the Internet being limited to brochure ware or Phase 1. A mean of 5.17 affirmed that respondents have not progressed in their use of the Internet for business solutions other than for use as brochure ware.

In response to Question A3 which asked if anyone provided IT support, including Web site design and/or maintenance, table 4 show that $82.2 \%$ (74 out of 90) report having IT support in or for their organization. Question A4 asked who was responsible for providing the IT support in the organization; contractors or external parties were named by $44.2 \%$ ( 34 out of 77 ), staff members whose main role was not IT support $(28.6 \%$, or 22 out of 77 ), and full time IT support staff members $(23.4 \%$, or 18 out of 77$)$. Relatively few reported having a part-time IT support staff member (3.9\%, or 3 out of 77 ).

Respondents were asked about the types of Internet access utilized by their organizations in Question A5, as can be seen in table 5 ; ADSL connection was reported as their Internet access by a majority (58.4\%, or 52 out of 89 ), followed by modem (13.5\%, 12 out of 89), ISDN (13.5\%, 12 out of 89 ), cable (14.6\%, 13 out of 89), wireless (20.2\%, 18 out of 89$)$, and satellite $(1.1 \%, 1$ out of 89$)$. Nearly $6 \%$ (5 out of 89$)$ were unsure of what their Internet access connection was, while $6.7 \%$ ( 6 out of 89 ) reported having a T1 line that provided Internet access, an option not listed in the survey but mentioned spontaneously by six respondents.

Table 6 shows that Of the 72 SMEs responding to Question A9, concerning the percentage of the previous fiscal year's budget spent on IT, a majority (51.4\%, 37 out of 72$)$ reported spending less than $2 \%$ on IT.

Question B2 presented the respondents with a list of options concerning how the Internet was used as a business tool in their organization. table 7 frequencies shows that a majority used the Internet for email $(96.7 \%, 88$ out of 91), for their Web sites (79.1\%, 72 out of 91); fewer use it for EDI (33\%, 30 out of 91), VOIP, which is the transmission of phone calls over the Internet, $(6.6 \%, 6$ out of 91$)$, and virtual meetings (11\%, 10 out of 89$)$. The most common answer in the "other" category (13 in total) was for research and/or procurement.

\section{Findings: Research Question 1}

What is the extent of use of the Internet as a business tool by SMEs?

\section{Finding 1:1}

Relatively few of the SMEs surveyed as part of this study had progressed beyond brochure ware and most continued to limit their use of the Internet for Web sites that provide basic information about their products and services, and contact information (Phase I). Two of the 77 (2.5\%) respondents reported having a Web site that provides for an integrated system that includes both front office and back office applications, and 8 of the 77 $(10.3 \%)$ respondents allowed customers to track the status of their orders. These 2 measures defined Phase III as the integration phase. Based on the previously described system of awarding points for each one of the 13 categories for Web site involvement, a total of 12 or 13 points constituted integration. Only one respondent achieved a score of $12(1.3 \%, 1$ out of 77$)$, and none received 13. The transaction phase, defined as Phase II, was measured by activities that included provision of a secure or non-secure form for ordering products/services that can be submitted online, an online system that allows customers to browse and order products/services but may or may not handle payments, and a fully integrated online transaction system that allows customers to browse/order products/services and pay for them using a credit card or some form of electronic payment. When points were awarded to each of the measures, based on the previously described system of awarding points for each one of the 13 categories for Web site involvement, a total of 8 to 11 points constituted attainment of the integration phase. Four respondents achieved a score of $8(5.2 \%, 4$ out of 77$), 5$ a score of $9(6.5 \%, 5$ out of 77$)$, and 1 a score of $11(1.3 \%, 1$ out of 77). The mean for phase totals was 5.17 and the median, 5.00 Analysis of the SMEs included in the study revealed that in spite of the fact that all were provided with up front services such as Web site design and training sessions on how to market on the Internet, and $75 \%$ of respondents (three out of the four still in business) continued to maintain a Web site, none had progressed beyond using their Web sites for limited purposes. The most advanced of the three provided an online form for customers and suppliers to contact them/make enquiries.

Finding 1:2 
A vast majority (82.2\%) of respondents reported having IT support in or for their organization, with the majority $(44.2 \%)$ indicating IT support was provided by contractors or external parties. A majority $(58.4 \%)$ of the 89 responses to the question about their Internet access indicated that ADSL was their means of connection. Of the 72 SMEs that responded to Question A9 concerning the percentage of the previous year's fiscal budget spent on IT, approximately $66.7 \%$ reported spending less than $3 \%$ on IT. Question B2 presented the respondents with a list of options concerning how the Internet was used as a business tool in their organization. A majority uses the Internet for e-mail (96.7\%) and for their Web sites (79.1\%), and much fewer used it for EDI (33\%). The profile for those who had progressed beyond Phase I (brochure ware) and had moved into Phase II (transactions) and Phase III (integration) included IT support being provided by either a staff member whose main responsibility is not IT supported (four respondents) or an external contractor (four respondents), ADSL providing the means of Internet access, spending greater than $5 \%$ of their budget on IT, the use of EDI, and movement into use of wireless and satellite access to the Internet.

\section{Research Question 2}

A majority (58.8\% or 40 out of 68 ) reported establishing their own Web site on the Internet in/or before 2000. Is the establishment of a Web site by SMEs the first stage in further involvement with use of the Internet as a business solution? Tables $(8,9,10)$ show the frequencies of the involvement with website

Nearly 88 percent of 100 respondents indicated that they used the Internet in the business activities of their organization. When they were asked what year they first started using the Internet in their organization, a majority of respondents $(55.6 \%$, or 45 out of 81$)$ reported having started their use of the Internet in or before the year 1999, and 79\% (64 out of 81) report having started their use of the Internet in or before the year 2000.

\section{Findings: Research Question 2}

\section{Finding 2:1}

A majority of respondents either used the Internet in the business activities of their organizations and/or had established a Web site, with 59 out of $69(85.5 \%)$ of respondents reporting they had established a Web site. However, a majority had not progressed beyond use of the Web for brochure ware (Phase I). Only 10 out of 69 with Web sites (14.4\%) tallied scores of 8 or more, indicating progression from Phase I (brochure ware) into Phase II (transactions) or Phase III (integration). The highest score achieved by a respondent (established in 2005) was 12 out of 13 . No company reported having a fully integrated business system that included both front office (such as selling activities) as well as back office applications (such as purchasing). Having access to the Internet or establishing a Web site did not lead to further involvement with Internet and/or the Web by respondents

\section{Finding 2:2}

It is unclear if the length of time on the Internet or the Web had bearing on the progression from Phase I to Phase II or Phase II. A majority (64\%, 7 out of 11$)$ of Phase II and Phase III responders reported having established their Web sites in or before 2000; while a majority $(62 \%, 41$ out of 66$)$ of Phase I responders also reported having established their Web sites in or before 2000. Similar patterns were noted when percentages are compared with use of the Internet; a majority ( $82 \%, 9$ out of 11$)$ of Phase II and Phase III responders established use of the Internet in or before 2000 as did a majority $(80 \%, 36$ out of 45$)$ of Phase I responders. Although several researchers had explored the concept of a staged approach to ebusiness (Poon, 1999; Metts, Monge, \& Rao, 2003; Mandel \& Hof, 2001; Kalakota \& Robinson, 2001; Dholakia \& Kshetri, 2004), others had proposed that SMEs' greater use of the Internet was achieved caused by characteristics of the entrepreneur and his/her attitude toward growth, the firm, and its context (Levy \& Powell; Storey, 1994).

\section{Research Question 3}

What were the important drivers that motivated SMEs to implement use of the Internet as a business tool?

Survey question B1 asked respondents who in the organization was the main initiator of use of the Internet as a business tool. The frequencies of the responds about the main initiator show Nearly $62 \%$ (53 out of 86) reported that the owner was the main initiator, followed by an employee (14.0\%, 12 out of 86$)$, and a customer $(10.5 \%, 9$ out of 86). Eight percent ( 7 out of $86 \%$ ) responded with "other" but were not asked to provide any detail see table 11.

Question B3 presented the respondent with a list of possible reasons which might have motivated the organization to implement use of the Internet as a business solution (see table 12). Survey participants were asked to a respond to a five point scale ranging from "strongly agree" to "strongly disagree" with an option for "not applicable in our case." Of the 90 companies that responded to question B3, a majority (54.4\%, 49 out of 90) 
agreed/strongly agreed that customer demands motivated the organization to implement use of the Internet as a business tool, and $57.2 \%$ (52 out of 91) disagreed/strongly disagreed with the statement that supplier pressure was a motivation to their decision. Although $40 \%$ (36 out of 91) agreed/ strongly agreed that competitive pressure was a factor in their decision to implement use of the Internet, $34.1 \%$ (31 out of 91) indicated that competitive pressure was not a factor in their decision. Incentives did not play a major role, with over $70 \%$ (64 out of 91) disagreeing/strongly disagreeing with the statement that the decision was made because of offered incentives. Eighty-two percent (75 out of 91) agreed or strongly agreed with the statement that the organization implemented use of the Internet because it suited its way of doing business. While 44\% (40 out of 91) of respondents disagreed / strongly disagreed that reduction of administrative costs was a motivator, nearly $32 \%$ (29 out of 91) agreed/strongly agreed that reduction of administrative costs was not a motivator. Also not viewed as a motivator was reduced production costs (61.5\% disagree/strongly disagree, 56 out of 91$)$, reduced distribution costs $(57.1 \%$ disagree/strongly disagree, 52 out of 91$)$, reduced personnel costs $(55.6 \%$ disagree/strongly disagree, 50 out of 90$)$, inventory costs ( $70.3 \%$ disagree/strongly disagree, 64 out of 91$)$, and improved inventory management (61.5\% disagree/strongly disagree, 56 out of 91$)$. However, after the questions in the survey turned to activities such as marketing, customers, and sales, the responses became more positive: $85.6 \%$ agree/strongly agree ( 77 out of 90 ) that use of the Internet as a business tool was implemented because it was believed it improved customer service, $83.5 \%$ agreed/strongly agreed (76 out of 91 ) that it improved marketing, $81.3 \%$ agreed/strongly agreed ( 74 out of 91 ) that it allowed them to reach new customers, and $79 \%$ agreed/strongly agreed (72 out of 91 ) that it improved competitiveness. However, after the questions turned from external activities focused on sales and marketing, and focused on internal management activities, such as lead times, organizational control, and operational efficiency, responses once again became negative. A majority $(41.8 \%)$ disagreed/strongly disagreed (38 out of 91 ) with the statement that reduced lead time from order to delivery was a motivator, and $46.2 \%$ (42 out of 91) disagreed/strongly disagreed with the statement that a higher degree of control in managing the organization was a motivator. However, a majority (49\%, 44 out of 90) agreed/strongly agreed with the statement that operational efficiency within the organization was a reason their company implemented use of the Internet as a business tool. Additional comments (a total of 25) focused on motivations such as enhanced communications (five responses), the ability to procure and conduct research (five responses), customer/supplier/competitor pressure (six), and greater promotion, geographic coverage, and reaching new markets (seven).

\section{Finding 3:1}

As indicated by a majority of respondents, the main initiator of use of the Internet is the business owner, followed by customers and competitors; suppliers do not appear to play much of a role. For those governmental, academic, and business organizations who seek to assist small and medium-sized organizations in their ability to grow, become more profitable, and improve performance, through technology and/or use of the Internet, they would profit from focusing their efforts on educating the owners on the benefits, especially as they relate to back office operations, cost savings, efficiencies, and the ability to be competitive in an ever-increasing competitive global marketplace. In addition, because of the fact that over $82 \%$ agreed or strongly agreed ( 75 out of 91 ) with the statement that the organization had implemented use of the Internet because it suited its way of doing business and because so few have progressed beyond use of the Internet for simple Web sites, owners of all small and medium-sized organization need to be made aware of how expansive the power of the Internet has become and how information technology costs and capabilities are no longer the purview of large companies but are within range of most SMEs.

\section{Finding 3:2}

Outside of the SMEs who did have upfront assistance, incentives did not play a major role in motivating respondents to embrace the Internet as a business tool. Because published literature on the topic of SMEs and the Internet is resplendent with examples of how other governments around the world are using incentives to motivate their SMEs to use the Internet, the use of incentives may be an area to be explored by governmental, academic, and business organizations.

\section{Finding 3:3}

SMEs appeared to be unaware of how the Internet can be used to enhance back room operations, improve supply chain management, improve lead times, reduce distribution, production, and personnel costs, or they did not see it being relevant to their business. The one area they do see as relevant was sales and marketing, the traditional functions of Phase I Web sites that allowed respondents to provide customer service, reach new customers, and 
improve competitiveness. A majority of the additional comments provided by respondents further emphasized this focus on marketing-oriented initiatives.

\section{Research Question 4}

What difficulties did SMEs) encounter while implementing use of the Internet as a business tool?

Table 13 shows the descriptive statistics of the difficulties that face internet use.

Research question B4 is addressed by analyzing responses to survey questions B4a through B4j. A majority $(58.2 \%, 53$ out of 91$)$ disagreed/strongly disagreed with the statement that they experienced difficulties changing their business processes to fit the use of the Internet, $44.4 \%$ (40 out of 90) indicated they did not have difficulty obtaining the expertise to assist with the Internet implementation, nor did a majority $(53.3 \%, 48$ out of 90$)$ believe they had difficulty integrating existing IT systems with use of the Internet as a business solution. However, nearly as many companies agreed/strongly agreed $(40 \%, 36$ out of 90$)$ with the statement they had difficulty choosing the most appropriate Internet system/technology as did those who disagreed $(37.8 \%, 34$ out of 90). Similarly split, were the responses to the question asking if purchasing the most appropriate Internet system/technology was difficult, with $37.8 \%$ disagreeing/strongly disagreeing (34 out of 90 ) that purchasing the right technology was difficult, but 40\% (36 out of 90) believed that it was a difficult task. Most respondents did not believe gaining acceptance from employees was difficult, with 55.6\% (50 out of 90) either disagreeing or strongly disagreeing with the statement. Resolving technical issues with customers was not a difficulty for $47.8 \%$ (43 out of 90), but a greater number disagreed or strongly disagreed with the statement that they had experienced difficulties resolving technical issues with suppliers $(58.9 \%, 53$ out of 90$)$. Lastly, determining the total cost of the Internet implementation was almost equally split between those respondents who experienced difficulty (35.6\% disagree/strongly disagree, 32 out of 90$)$ and those who did not (32.2\% agree/strongly agree, 29 out of 90). In additional comments (22 in all), predominantly (12) centered on difficulties experienced with technology (knowledge, performance, service) with fewer comments expressed about difficulties with abuse and/or lack of trust by employees (five respondents), compatibility with product line (two respondents), and costs and scheduling (three respondents).

\section{Finding 4:1}

Respondents were asked a variety of questions concerning difficulties experienced while implementing use of the Internet for business solutions. Although none of the possibilities listed in the survey were identified by a majority of respondents as being an issue during the implementation phase, some respondents did experience difficulty with changing business processes to fit use of the Internet, obtaining the expertise necessary with implementation, and determining the total cost of Internet implementation. The only area that appeared not to have given the respondents difficulty was obtaining employees' acceptance of use of the Internet. In several cases, such as difficulty choosing or purchasing the most appropriate Internet system/technology and difficulty determining the total cost of the Internet implementation, the responses were nearly equally split between those who agreed and those who disagreed.

\section{Research Question 5}

What were the benefits that have accrued to those SMEs that had adopted use of the Internet as a business tool?

Survey questions B5a through B5o illuminated the various benefits that had been experienced by respondents since implementing use of the Internet as a business tool (see table 14). Of the 91 who answered the question about a reduction in administrative costs, $45 \%$ (41 out of 91) disagreed/strongly disagreed with the statement that they had experienced such a reduction. Even fewer reported experiencing a reduction in production costs $(56 \%$, 51 out of 91$)$, a reduction in distribution costs $(49.4 \%, 45$ out of 91$)$, a reduction in personnel costs $(49.4 \%, 45$ out of 91$)$, or a reduction in inventory costs $(59.3 \%, 54$ out of 91$)$, nor did they report experiencing improved inventory management $(48.3 \%, 44$ out of 91$)$. Once again, the percentages became positive as the questions centered on marketing, customer service, and revenue. Nearly $85 \%$ (77 out of 91) agreed/strongly agreed with the statement that they have experienced improved customer service, improved marketing $(82.2 \%, 74$ out of 90$)$, increased customer base $(68.9 \%, 62$ out of 90$)$, increased revenue $(63.3 \%, 57$ out of 90$)$, and improved competitiveness $(73.3 \%, 66$ out of 90$)$. Responses to the question asking if lead time from order to delivery had been reduced were nearly equally split between those who disagreed/strongly disagreed (33.3\%, 30 out of 90$)$ and those who agreed/strongly agreed (35.6\%, 32 out of 90); 35.6\% disagreed/strongly disagreed (32 out of 90) with the statement that they experienced a higher degree of control in managing their business, but improved operational efficiency was reported by $45 \%$ (41 out of 91) as being a benefit. Additional comments (a total of 23) included benefits of marketing, promotion, and expanded geographic markets (nine), expansion of information 
dissemination to employees and others (five), the saving of time and money (four), and the ability to conduct research (five). When comparisons are made between the reasons that may have motivated the organization to implement use of the Internet and those of benefits that respondents experienced since implementing use of the Internet as a business tool, similarities are observed. For example, a majority of respondents indicated that improved operational efficiency was both a driver as well as a benefit; a majority agreed that improved competitiveness was both a motivator for implementing use of the Internet as well as a benefit, and a majority agree/strongly agree that increased revenue was both a motivator as well as an experienced benefit. Similar comparisons occurred with issues of reaching new customers, improved marketing, and improved customer service. Conversely, a majority of respondents disagreed with the statement that reduced lead time was a motivator, but a majority also disagreed that it was a benefit. Similar comparisons were evident in addressing the issue of a higher degree of control in managing the business (a majority disagreed that it was a motivator or a benefit), improved inventory management (a majority disagreed that it was a motivator or a benefit), or reduced personnel, distribution, production, administrative, inventory costs (a majority disagreed that they were motivators or benefits).

\section{Finding 5:1}

Respondents to survey questions B5a through B5n reported having experienced benefits of improved customer service, marketing, an increased customer base, increased revenue, an increase in improved competitiveness, and possibly, although it is not clear, improvement in lead time from order to delivery. Benefits such as reductions in administrative, personnel, distribution, personnel, and inventory costs were not reported by a majority of respondents as a benefit since implementing use of the Internet as a business tool by their respective organizations. Less clear is if small Minnesota-based manufacturers who implemented use of the Internet experienced benefits associated with greater control in managing their business or improved operational efficiency.

\section{Finding 5:2}

A majority of respondents who were motivated to implement use of the Internet as a business tool by expectations of externally-oriented drivers, such as an improvement in customer service, marketing, revenue, competitiveness, and an increase in their customer base, also experienced benefits in those same areas since implementing use of the Internet as a business tool. Inwardly-directed activities, such as a focus on reduction of administrative, production, personnel, inventory costs, and lead time from order to delivery and an improvement in inventory management and operational efficiency, were not motivations for the organizations to implement use of the Internet as a business tool and were not reported as a benefit. It appeared for a majority of respondents that expectations were in line with what was accomplished.

\section{Research Question 6}

What problems, such as cost increases, reductions in flexibility, security, and operational efficiencies, have SMEs encountered after implementing use of the Internet as a business tool?

Research question 6 was addressed by analyzing responses to survey questions B6a through B6 ( see table 15) which $63.3 \%$ (57 out of 90) agreed/strongly agreed that one of the problems they had experienced since implementing use of the Internet as a business tool was an increase in the amount of resources spent on IT maintenance. Nearly $78 \%$ (70 out of 90 ) disagreed/strongly disagreed with the statement that the Internet had reduced the organization's flexibility, and 63.3\% (57 out of 90) did not believe they had duplicated any business process as a result of implementing use of the Internet as a business tool. A reduction of IT security as a difficulty was nearly split between those respondents who indicated a reduction of IT security (34\% agreed/strongly agreed, 31 out of 90 ) and those who did not (40\% disagreed/strongly disagreed, 36 out of 90). Greater numbers of respondents disagreed/strongly disagreed with the statement that they had experienced difficulty with duplicated business processes $(63.3 \%, 57$ out of 90$)$, deteriorated relations with either customers $(86.7 \%, 78$ out of 90$)$ or suppliers $(82.2 \%, 74$ out of 90$)$, increased production costs $(80 \%, 72$ out of 90$)$, increased distribution costs $(78.9 \%, 71$ out of 90$)$, increased personnel costs $(78.9 \%, 72$ out of 90$)$, increased inventory costs $(78.9 \%, 71$ out of 90$)$, or reduced operational efficiency $(73 \%, 65$ out of 89$)$. Nearly equal responses were given to the question asking if increased administrative costs had been incurred, with $36.7 \%$ (33 out of 90) agreeing/strongly agreeing they had experienced an increase in administrative costs and $38.9 \%$ (35 out of 90) disagreeing/strongly disagreeing with the statement. Additional comments were made by 15 respondents concerning technology changes, updates, and problems reported by a majority (seven), the creation of more work (two), and proper use by employees (two).

Finding 6: 
The one problem that appeared to have been experienced by a majority of small and medium sized manufacturers since implementing use of the Internet as a business tool was one of an increase in the amount of resources spent on IT maintenance. Less clear was if a reduction of IT security or an increase in administrative costs had been a problem for most; however, most respondents did not believe they had experienced difficulty with duplicated business processes, deteriorated customer and/or supplier relations, increased production, distribution, personnel, or inventory costs, and reduced operational efficiency. Section D allowed for additional comments. Three respondents indicated the importance of optimizing Web sites, two indicated that the Internet and Web sites were unimportant, one expressed concern about employees wasting time on the Internet, and one stated the survey was too long.

\section{Analysis by Hypothesis}

In addition to the descriptive analysis applied in order to understand better the characteristics of the sample, statistical tests were used to examine the relation between the independent variable (Internet adoption by small and medium sized manufacturers) and dependent variables, such as progression from Phase I (brochure ware) to Phase II (transactions) and Phase III (integration), establishment of a Web site as a first step to further involvement with the Internet, drivers of adoption, benefits achieved, and difficulties and problems experienced before and after implementation of use of the Internet as a business solution. Following is a review of each hypothesis.

Hypothesis 1

Ho1: A majority of SMEs in KSA use the Internet for business solutions other than having Web sites for promotional purposes.

HA1: A majority of SMEs in KSA do not use the Internet for business solutions other than having Web sites for promotional purposes.

A single population proportion test was performed to determine the statistical significance of the extent of Internet usage. The results of the testing of hypothesis 1 are presented in Table 16. The test was significant at the 0.5 level, $\mathrm{z}=6.49$; the researcher, therefore, rejects the null hypothesis designated Hol and accepts the alternative hypothesis designated HA1. The research findings are statistically significant in the explanation of the extent of Internet usage by SMEs for business solutions and support the hypothesis that a majority does not use the Internet for business solutions other than having Web sites for promotional purposes.

Hypothesis 2

Ho2: The establishment of a Web site is related to further involvement with the Internet for business solutions.

HA2: The establishment of a Web site is not related to further involvement with the Internet for business solutions.

A one way paired $\mathrm{z}$ test was performed to determine the statistical significance difference between the sample distribution mean of Phases I, II, and III and the parameter of 13 total possible points. The results of the testing of hypothesis 1 are presented in Table 17. The test was significant at the 0.5 level, $\mathrm{z}=-4.963$; the researcher, therefore, rejects the null hypothesis designated Hol and accepts the alternative hypothesis designated HA1. The research findings are statistically significant in the explanation of Web sites and their relation to further involvement with the Internet for business solutions and support the hypothesis the establishment of a Web site is not related to further involvement with the Internet for business solutions.

\section{Hypothesis 3}

Ho3: There is no one factor that is more important than others that influences SMEs in their adoption of the Internet for business solutions.

HA3: There is a hierarchy of factors, such as competitive, customer, and supplier pressure, that influence SMEs) in their adoption of the Internet for business solutions

The results of the one-way analysis of variance (ANOVA) testing of hypothesis 3 are presented in Table 18 . Because the calculated value is greater than the critical value, the researcher rejects the null hypothesis designated $\mathrm{Ho} 3$ and accepts the alternative hypothesis designated HA3, concluding there are significant differences between two or more pairs of means.

\section{Hypothesis 4}

Ho4: There were no difficulties experienced by SMEs in their adoption of the Internet for business solutions. 
HA4: SMEs experienced difficulties, such as the cost of hardware and software in their adoption of the Internet for business solutions.

The results of the one-way analysis of variance (ANOVA) testing of hypothesis 4 are presented in Table 19 . Because the calculated value is greater than the critical value, the researcher rejects the null hypothesis designated Ho4 and accepts the alternative hypothesis designated HA4, concluding there are significant differences between two or more pairs of means.

\section{Hypothesis 5}

Ho5: SMEs who use the Internet for business solutions have realized few benefits.

HA5: Benefits, perceived and real, such as an increase in sales, decrease in costs, and improved efficiencies, have been realized by SMEs that adopted use of the Internet as a business tool.

The results of the one-way analysis of variance (ANOVA) testing of hypothesis 5 are presented in Table 20 . Because the calculated value is greater than the critical value, the researcher rejects the null hypothesis designated Ho5 and accepts the alternative hypothesis designated HA5, concluding there are significant differences between two or more pairs of means.

\section{Hypothesis 6}

Ho6: There have been no problems, such as cost increases, reductions in flexibility, security, and operational efficiencies, experienced by SMEs since their adoption of the Internet for business solutions.

HA6: SMEs have experienced problems, such as cost increases, reductions in flexibility, and duplication of business processes, following their implementation of an Internet strategy.

The results of the one-way analysis of variance (ANOVA) testing of hypothesis 5 are presented in Table 21 . Because the calculated value is greater than the critical value, the researcher rejects the null hypothesis designated Ho6 and accepts the alternative hypothesis designated HA6, concluding there are significant differences between two or more pairs of means.

First we described the 100 respondents using descriptive analysis. Then presented the statistical analysis by hypothesis. All hypothesis were tested at the $\mathrm{p}<0.05$ level. The null hypotheses for all hypotheses 1 through 6 were all rejected. The research findings are all statistically significant in the examination of the relation between Internet adoption by SMEs and the progress made from Phase I (brochure ware) to Phase II (transactions) and Phase III (integration), the establishment of a Web site as a first step to further involvement with the Internet, drivers of adoption, benefits achieved, and difficulties and problems experienced before and after implementation of use of the Internet as a business solution.

\section{Conclusions and recommendation for future research}

The global economy is made up of a large number of SMEs who are the largest employers of many of the world's citizens. The literature indicated governments around the globe are concerned about the failure of their SMEs to adopt and exploit Internet technology and are putting programs and incentives in place to encourage greater involvement with the Internet. While SMEs in KSA are perceived to be advanced in their use of the Internet and WWW, data was scarce with most of the research focusing on larger companies. This study found statistical significant support for the hypotheses that a majority of SMEs do not use the Internet for business solutions other than establishing Web sites for promotional purposes, nor does the establishment of a Web site lead to further involvement with use of the Internet for business solutions. This study found statistical significant support for the hypotheses that there is a hierarchy of factors influencing adoption of the Internet as a business tool. Regarding difficulties experienced during implementation of the use of the Internet as a business tool, very little exists in the way of published literature. This paucity of research is in contrast to the amount of research published on the topic of barriers to e-commerce adoption by SMEs. This study supported the hypotheses that in spite of the perception that Saudian's SMEs are advanced in their use of the Internet as a business tool, most SMEs have limited their use of the Internet and/or Web sites to brochure ware or as a one way means of communication with external audiences and having a Web site does not lead to further involvement with use of the Internet as a business tool. According the practical implications of these findings and suggestions for future research, It is recommended that future research be expanded to include many sectors of the economy, including finance, retail, and agriculture. This study investigated only SMEs in the manufacturing. The study of other sectors may contribute to a more complete picture of the current status of the adoption progress of the Internet as a business tool. It is recommended that future research be conducted into the current level of understanding by SMEs Presidents, Owners, or CEOs about the use of the Internet as a business tool beyond the establishment of 
Web sites as brochure ware, including their level of understanding about terms such as e-business, e-commerce, Internet marketing. It is recommended that future research be conducted to determine what the most effective means are to educate, inform, and motivate the Presidents, Owners, or CEOs to take a proactive stance with regard to use of the Internet for business solutions. It is recommended that future research on use of the Internet as a business tool delve more deeply into issues relating to drivers of adoption, the difficulties experienced during implementation of an Internet-based IT system, the benefits achieved, and the problems experienced since implementation. Finally, it is recommended that future research investigate the level of influence and pressure that is being applied by large companies on their small business suppliers to become more involved with use of the Internet as a business tool.

\section{References}

Abouzeedan, A. \& Busler, M. (2002). Information Technology (IT) Impact on Performance of Small and Medium Enterprises (SMEs). Proceedings of RENT XVI, Research in Entrepreneurship and Small Business.

Aljitri, H. A., Pons, A. \& Collins, D. (2003). Global E-Commerce: A Framework for Understanding and Overcoming The Trust Barrier. Information Management.

Al-Qirim, N. (2006). Personas of E-commerce adoption in small businesses in New Zealand.

Beach, R. (2004). Adopting Internet technology in manufacturing: a strategic perspective. Production Planning \& Control, 15(1), 80-89. http://dx.doi.org/10.1080/09537280410001662574

Beal, T. (2001). Government Promotion and Facilitation of ICT Use by SMEs: APEC and New Zealand. Asia Small Business Review.

Becherer, R. C., Haynes, P. J. \& Helms, M. M. (1998). Small and mid-sized businesses and Internet use: unrealized benefit? Internet Research, 8(3), 229-235. http://dx.doi.org/10.1108/10662249810217786

Creswell, J. W. (2003). Research design: qualitative, quantitative and mixed methods approaches. (2nd ed.). Thousand Oaks, CA: SAGE Publications.

Economic Pannning Unit. Ninth Malaysian Plan 2006-2010, Publication and DISTR, Putrajaya.

Economic Planning Unit. Eighth Malaysian Plan 2001-2005, Publication and DISTR, Putrajaya.

Elder, A., Litan, R. E., Shutter, J. \& Varian, H. (2002, January). The Net Impact Study: the projected economic benefits of the Internet in the United States, United Kingdom, France and Germany (v2.0): Momentum Research Group.

Eriksson, L.T. \& Hultman, J. (2005). One digital leap or a step-by-step approach? - An empirical study of e-commerce development amongst Swedish SMEs. International Journal of Electronic Business, Vo 3, No.5.

Gibbs, J. L. \& Kraemer, K. L. (2004). A crosscountry investigation of the determinants of scope of e commerce use: an institutional approach. Electronic Markets.

Harindranath, G. Dyerson, R. \& Barnes, D. (2008). ICT Adoption and Use in UK SMEs: a Failure of Initiatives? The Electronic Journal of Information Systems Evaluation, Volume 11 Issue 2.

Heinz Hollenstein \& Martin Woerter, (2007). Inter- and Intra-Firm Diffusion of Technology: the Example of E-commerce: An Analysis based on Swiss Firm-level Data. KOF Working papers 07-157, KOF Swiss Economic Institute, ETH Zurich. [Downloadable!] Other versions:

Hussin, H. \& Noor, R. M. (2005). Innovating Business through E-Commerce: Explore the Willingness of Malaysian SMEs. Proceedings of the Second International Conference on Innovation in IT.

James, J. (2003). Sustainable Internet access for the rural poor? Elements of an emerging Indian model. Futures, 35:5. http://dx.doi.org/10.1016/S0016-3287(02)00092-7

Jeff Hoi, Y.Y, Shim, J.P. \& Andy, Yin K.L. (2003). Current Progress of E-Commerce Adoption: Small and Medium Enterprises in Hong Kong. Communication of the ACM, (46:9).

Kalakota, R. \& Robinson, M. (2001). e-Business 2.0 roadmap for success (2.0 ed.). New Jersey: Addison-Wesley.

Kalakota, R. \& Robinson, M. (2001). M-business: the road to mobility. Ohio: McGraw-Hill.

Kalakota, R. \& Robinson, M. (2001). E-business 2.0, (2nd ed). Addison-Wesley, Canada.

Kleindl, B. (2000). Competitive dynamics and new business models for SMEs in the virtual marketplace.

Journal of Developmental Entrepreneurship, 5, 73-86. 
Levy, M., Powell, P. \& Worrall, L. (2005). Strategic intent and e-business in SMEs: Enablers and inhibitors. Information Resources Management Journal, Vol. 18, No. 4. http://dx.doi.org/10.4018/irmj.2005100101

Limthongchai, P. \& Speece, M. W. (2003). The Effect of Perceived Characteristics of Innovation on E Commerce Adoption by SMEs in Thailand, Proceedings of the Seventh International Conference on Global Business and Economic Development, Bangkok, Thailand.

MacGregor, R. \& Vrazalic, L. (2004, May). Electronic commerce adoption in small and medium enterprises (SMEs). Wollongong: University of Wollongong.

Mahesha Kapurubandara \& Robyn Lawson. (2006). Barriers to Adopting ICT and e-commerce with SMEs in Developing Countries: An Exploratory study in Sri Lanka.

Martin, Ludivine. (2009). Understanding the implementation of e-business strategies: Evidence from Luxembourg. MPRA Paper 13645, University Library of Munich, Germany. [Downloadable!]

Organisation for Economic Corporation and Development. (2004). ICT, e-Business and SMEs. Paris.

Pavic, S., Koh, S.C.L. Simpson., M. \& Padmore, J. (2007). Could e-business create a competitive advantage in UK SMEs? Benchmarking: An International Journal, Vol. 14, No. 3.

Piergiuseppe Morone \& Giuseppina Testa. (2005). What Makes Small and Medium Enterprises Competitive. Quaderni DSEMS 18-2005, Dipartimento di Scienze Economiche, Matematiche e Statistiche, Universita' di Foggia. [Downloadable!]

Pool, P.W., Parnell, J.A., Spillan, J.E., Carraher, S. \& Lester, D.L. (2006). Are SMEs meeting thechallenge of integrating e-commerce into their businesses? A review of the development, challenges andopportunities. International Journal of Information Technology and Management, Vol. 5, No 2/3. http://dx.doi.org/10.1504/IJITM.2006.010112

Porter, M. E. (2001). Strategy and the Internet. Harvard University Review, 79:3.

Rola, M. (2002). Small and medium enterprises wary of high e-business costs. Computing Canada, 28 (22), 13.

Sekaran, U. (2003). Research Methods for Business: A Skill Building Approach (4th ed.), John Wiley \& Sons.

Shape the future. (2008). UK Small Medium Enterprises. [Online] Available: http://files.shape-thefuture. com/reports/Zen/SME_ISP_Survey.pdf

Slyke, C. V., Belanger, F. \& Comunale, C. L. (2004). Factors Influencing the Adoption of Web-Based Shopping: The Impact of Trust. Database for Advanced in Information Systems, (35:2).

Slyke, C. V., Belanger, F. \& Hightower, R. (2005). Understanding Gender-Based Differences in Consumer E-Commerce Adoption. Proceedings of the 2005 Sounthern Association of Information Conference.

Soliman, K. S. (2003). Internet-based business-to-business electronic commerce: a CIO's perspective. Information Systems Management, Winter, 35. http://dx.doi.org/10.1201/1078/43203.20.1.20031201/40082.5

Subramaniam, R. \& Talha, M. (2003). Role of e-commerce in economic growth. Journal of Internet Marketing, $4(1), 1-5$.

Syed S.A, Ali, K, Hishamuddin, B.I. \& Ismail, A. (2005). Perceived Benefits of E-Commerce Adoption in the Electronic Manufacturing Companies in Malaysia. Journal of Social Sciences, 1:3.

Wymer, S.A. \& Regan, E.A. (2005). Factors influencing e-commerce adoption and use by small and medium businesses. Electronic Markets, Vol. 15, No. 4. http://dx.doi.org/10.1080/10196780500303151

Table 1. Frequency for extent use of internet

\begin{tabular}{|c|c|c|c|c|c|c|}
\hline \multicolumn{2}{|c|}{ Statement } & Missing & Frequency & Percent & $\begin{array}{l}\text { Valid } \\
\text { percent }\end{array}$ & Cumulative\% \\
\hline \multicolumn{7}{|c|}{ Use internet? } \\
\hline \multirow[t]{2}{*}{ Valid } & Yes & & 87 & 87.0 & 87.0 & 87.0 \\
\hline & No & & 13 & 13.0 & 13.0 & 100.0 \\
\hline \multicolumn{2}{|l|}{ Total } & & 100 & 100.0 & 100.0 & \\
\hline \multicolumn{2}{|c|}{ Web site? } & 1 & & 1.0 & & \\
\hline \multirow[t]{2}{*}{ Valid } & Yes & & 71 & 71.0 & 71.7 & 71.7 \\
\hline & No & & 28 & 28.0 & 28.3 & 100 \\
\hline \multicolumn{2}{|l|}{ Total } & & 99 & 100.0 & 100.0 & \\
\hline \multicolumn{2}{|c|}{ Business info? } & 23 & & 23.0 & & \\
\hline
\end{tabular}




\begin{tabular}{|c|c|c|c|c|c|}
\hline Yes & & 69 & 69.0 & 89.6 & 89.6 \\
\hline No & & 8 & 8.0 & 10.4 & 100.0 \\
\hline Total & & 77 & 100.0 & 100.0 & \\
\hline Product info? & 23 & & 23.0 & & \\
\hline Yes & & 71 & 71.0 & 92.2 & 92.2 \\
\hline No & & 6 & 6.0 & 7.8 & 100.0 \\
\hline Total & & 77 & 100.0 & 100.0 & \\
\hline Contact info? & 23 & & 23.0 & & \\
\hline Yes & & 68 & 68.0 & 88.3 & 88.3 \\
\hline No & & 9 & 9.0 & 11.7 & 100.0 \\
\hline Total & & 77 & 100.0 & 100.0 & \\
\hline E- mail link? & 23 & & 23.0 & & \\
\hline Yes & & 64 & 64.0 & 83.1 & 83.1 \\
\hline No & & 13 & 13.0 & 16.9 & 100.0 \\
\hline Total & & & 100.0 & 100.0 & \\
\hline $\begin{array}{l}\text { Online form for } \\
\text { customers? }\end{array}$ & 23 & & 23.0 & & \\
\hline Yes & & 49 & 49.0 & 63.6 & 63.6 \\
\hline No & & 28 & 28.0 & 36.4 & 100.0 \\
\hline Total & & 77 & 100.0 & 100.0 & \\
\hline $\begin{array}{l}\text { Online form for } \\
\text { suppliers? }\end{array}$ & 23 & & 23.0 & & \\
\hline Yes & & 23 & 23.0 & 29.9 & 29.9 \\
\hline No & & 54 & 54.0 & 70.1 & 100.0 \\
\hline Total & & 77 & 100.0 & 100.0 & \\
\hline $\begin{array}{l}\text { Online form for } \\
\text { faxing? }\end{array}$ & 23 & & 23.0 & & \\
\hline Yes & & 17 & 17.0 & 22.1 & 22.1 \\
\hline No & & 60 & 60.0 & 77.9 & 100.0 \\
\hline Total & & 77 & 100.0 & 100.0 & \\
\hline Non-secure form & 23 & & 23.0 & & \\
\hline Yes & & 3 & 3.0 & 3.9 & 3.9 \\
\hline No & & 74 & 74.0 & 96.1 & 100.0 \\
\hline Total & & 77 & 100.0 & 100.0 & \\
\hline secure form & 23 & & 23.0 & & \\
\hline Yes & & 14 & 14.0 & 18.2 & 18.2 \\
\hline No & & 63 & 63.0 & 81.8 & 100.0 \\
\hline Total & & 77 & 100.0 & 100.0 & \\
\hline Online system & 23 & & 23.0 & & \\
\hline Yes & & 5 & 5.0 & 6.5 & 6.5 \\
\hline No & & 72 & 72.0 & 93.5 & 100.0 \\
\hline Total & & 77 & 100.0 & & \\
\hline $\begin{array}{l}\text { Online } \\
\text { system }\end{array}$ & 23 & & 23.0 & & \\
\hline Yes & & 9 & 9.0 & 11.7 & 11.7 \\
\hline No & & 68 & 68.0 & 88.3 & 100.0 \\
\hline Total & & 77 & 100.0 & 100.0 & \\
\hline Tracking system? & 23 & & 23.0 & & \\
\hline Yes & & 8 & 8.0 & 10.4 & 10.4 \\
\hline No & & 69 & 69.0 & 89.6 & 100.0 \\
\hline Total & & 77 & 100.0 & 100.0 & \\
\hline Full integration? & 23 & & 23.0 & & \\
\hline Yes & & 2 & 2.0 & 2.6 & 2.6 \\
\hline No & & 75 & 75.0 & 97.4 & 100.0 \\
\hline Total & & 77 & 100.0 & 100.0 & \\
\hline
\end{tabular}


Table 2. Frequencies and Descriptive statistics Total of all phases

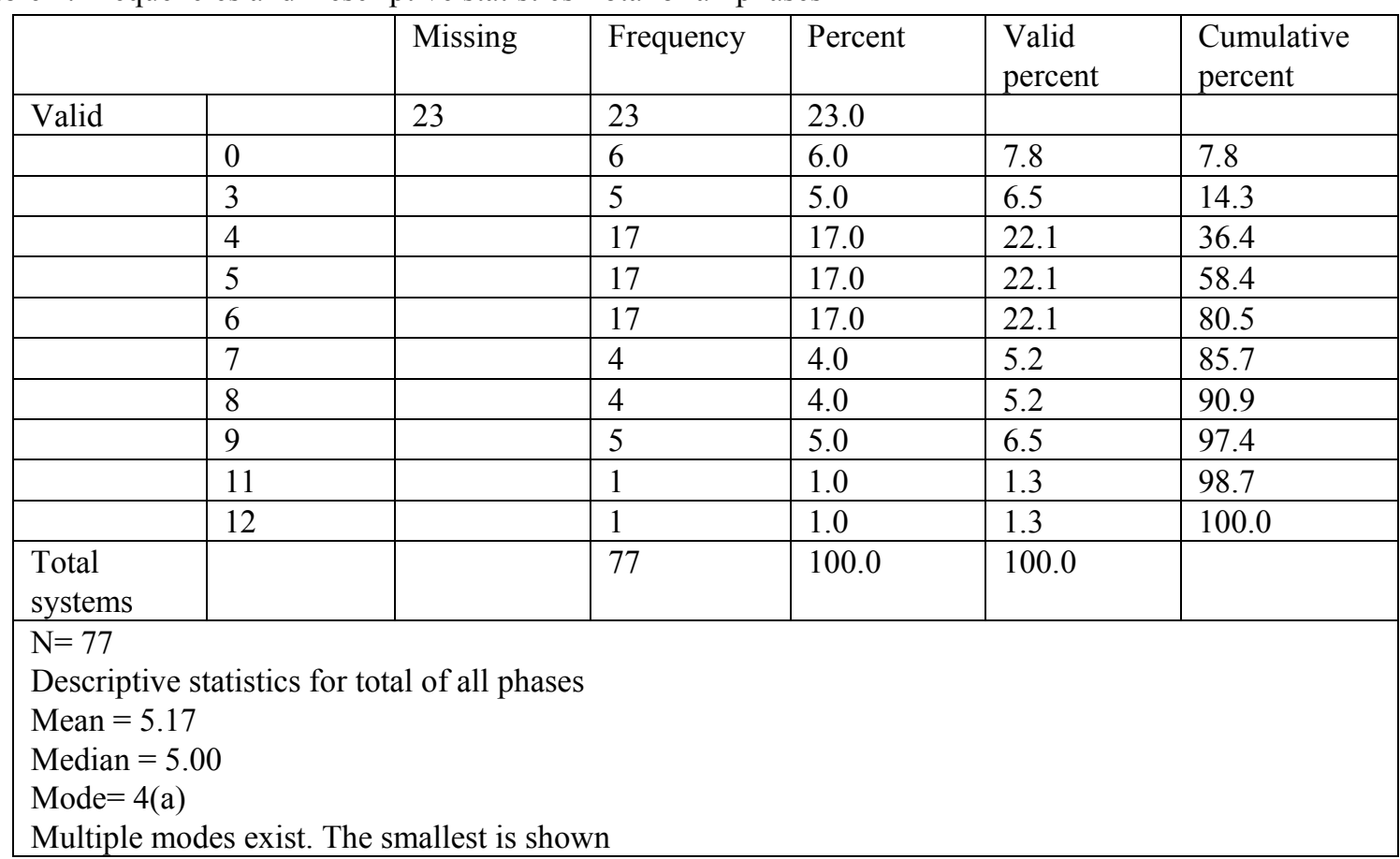

Table 3. Frequencies, phase 1 (brochure ware) 2 (transaction) 3 (integration) Totals

\begin{tabular}{|l|l|l|l|l|l|}
\hline & Missing & Frequency & Percent & Valid percent & $\begin{array}{l}\text { Cumulative } \\
\text { percent }\end{array}$ \\
\hline $\begin{array}{l}\text { Phase1: } 0-7 \\
\text { points }\end{array}$ & 23 & & 23.0 & & \\
\hline 0 points & & & & & \\
\hline 3 points & & 6 & 7.8 & 7.8 & 7.8 \\
\hline 4 points & & 5 & 5.0 & 6.5 & 14.3 \\
\hline 5 points & & 17 & 17.0 & 22.1 & 36.4 \\
\hline 6 points & & 17 & 17.0 & 22.1 & 58.4 \\
\hline 7 points & & 4 & 17.0 & 22.1 & 80.5 \\
\hline $\begin{array}{l}\text { Phase2:8- } \\
11 \text { points }\end{array}$ & & 4.0 & 5.2 & 85.7 \\
\hline 8 points & & 4 & & & \\
\hline 9 points & & 5 & 4.0 & 5.2 & 90.0 \\
\hline 11 points & & 1 & 5.0 & 6.5 & 97.4 \\
\hline $\begin{array}{l}\text { Phase3:12- } \\
13 \text { points }\end{array}$ & & & 1.0 & 1.3 & 98.7 \\
\hline 12 points & & & & & \\
\hline Total & 23 & 77 & 100.0 & 100.0 & \\
\hline N = 77 & & & & \\
\hline
\end{tabular}


Table 4. Frequencies of information technology support

\begin{tabular}{|l|l|l|l|l|l|}
\hline & Missing & Frequency & Percent & Valid percent & $\begin{array}{l}\text { Cumulative } \\
\text { percent }\end{array}$ \\
\hline IT support & 10 & & 10.0 & & \\
\hline Valid Yes & & 74 & 74.0 & 82.2 & 82.2 \\
\hline No & 16 & 16.0 & 17.8 & 100 \\
\hline Total & & 90 & 100.0 & & \\
\hline $\begin{array}{l}\text { Who is } \\
\text { responsible ? }\end{array}$ & 23 & & 23.0 & & \\
\hline Valid full time & & 18 & 18.0 & 23.4 & 23.4 \\
\hline Part time & 3 & 3.0 & 3.9 & 27.3 \\
\hline Not main role & & 22 & 22.0 & 28.6 & 55.8 \\
\hline Contractor & 34 & 34.0 & 44.2 & 100.0 \\
\hline Total & 77 & 100.0 & & \\
\hline N =77 & & & & \\
\hline
\end{tabular}

Table 5. Frequencies of type of internet access

\begin{tabular}{|l|l|l|l|l|l|}
\hline Statement & Missing & Frequency & Percent & $\begin{array}{l}\text { Valid } \\
\text { percent }\end{array}$ & Cumulative\% \\
\hline Modem & 11 & & 11.0 & & \\
\hline Valid Yes & & 12 & 12.0 & 13.5 & 13.5 \\
\hline No & & 77 & 77.0 & 86.5 & 100.0 \\
\hline Total & 11 & 89 & 100.0 & 100.0 & \\
\hline ADSL & 11 & & 11.0 & & \\
\hline Valid Yes & & 52 & 52.0 & 58.4 & 58.4 \\
\hline No & & 37 & 37.0 & 41.6 & 100.0 \\
\hline Total & 11 & 89 & 89.0 & 100.0 & \\
\hline ISDN & 11 & & 11.0 & & \\
\hline Valid Yes & & 12 & 12.0 & 14.6 & 14.6 \\
\hline No & & 77 & 77.0 & 85.4 & 100.0 \\
\hline Total & 11 & 89 & 100.0 & 100.0 & \\
\hline Cable & 11 & & 11.0 & & \\
\hline Valid Yes & & 13 & 13.0 & 14.6 & 14.6 \\
\hline No & & 76 & 76.0 & 85.4 & 100.0 \\
\hline Total & 11 & 89 & 100.0 & 100.0 & \\
\hline Wireless & 11 & & 11.0 & & \\
\hline Valid Yes & & 18 & 18.0 & 20.2 & 20.2 \\
\hline No & & 71 & 71.0 & 79.8 & 100.0 \\
\hline Total & 11 & 89 & 100.0 & 100.0 & \\
\hline Satellite & 11 & & 11.0 & & \\
\hline Valid Yes & & 1 & 1.0 & 1.1 & 1.1 \\
\hline No & & 88 & 88.0 & 98.9 & 100.0 \\
\hline Total & 11 & 89 & 100.0 & 100.0 & \\
\hline Not sure & 11 & & 11.0 & & \\
\hline Valid Yes & & 5 & 5.0 & 5.6 & 5.6 \\
\hline No & & 84 & 84.0 & 94.4 & 100.0 \\
\hline Total & 11 & 89 & 100.0 & 100.0 & \\
\hline T 1 & & 11.0 & & \\
\hline Valid Yes & 83 & 6.0 & 6.7 & 6.7 \\
\hline No & & 83.0 & 93.3 & 100.0 \\
\hline Total & & 100.0 & 100.0 & \\
\hline N = 89 & & & & \\
\hline & & & & \\
\hline
\end{tabular}


Table 6. Frequencies of percentage of budget spent on IT

\begin{tabular}{|l|l|l|l|l|l|}
\hline & Missing & Frequency & Percent & Valid percent & $\begin{array}{l}\text { Cumulative } \\
\text { percent }\end{array}$ \\
\hline & 28 & & 28.0 & & \\
\hline Valid & & & & & \\
\hline None & & 5 & 5.0 & 6.9 & 6.9 \\
\hline Less than 1 & 17 & 17.0 & 23.6 & 30.6 \\
\hline $\begin{array}{l}\text { Less than 1 to } \\
\text { under just 2 }\end{array}$ & 15 & 15.0 & 20.8 & 51.4 \\
\hline $\begin{array}{l}\text { Form 2 to just } \\
\text { under 3 }\end{array}$ & 11 & 11.0 & 15.3 & 66.7 \\
\hline $\begin{array}{l}\text { Form 3 to just } \\
\text { under 4 }\end{array}$ & 7 & 7.0 & 9.7 & 76.4 \\
\hline $\begin{array}{l}\text { Form 4 to just } \\
\text { under 5 }\end{array}$ & 9 & 9.0 & 12.5 & 88.9 \\
\hline $\begin{array}{l}\text { Form 5 to just } \\
\text { under } 10\end{array}$ & 7 & 7.0 & 9.7 & 98.6 \\
\hline $\begin{array}{l}\text { Form 10 to } \\
\text { just under 25 }\end{array}$ & 1 & 1.0 & 1.4 & 100.0 \\
\hline $\begin{array}{l}\text { Form 25 to } \\
\text { just under 50 }\end{array}$ & & & & & \\
\hline Total & 28 & 72 & 100.0 & 100.0 & \\
\hline N 72 & & & & \\
\hline
\end{tabular}

Table 7. Frequencies of how internet is used

\begin{tabular}{|l|l|l|l|l|l|}
\hline Statement & Missing & Frequency & Percent & $\begin{array}{l}\text { Valid } \\
\text { percent }\end{array}$ & Cumulative\% \\
\hline For e- mail & 9 & & 9.0 & & \\
\hline Valid Yes & & 88 & 88.0 & 96.7 & 96.7 \\
\hline No & & 3 & 3.0 & 3.3 & 100.0 \\
\hline Total & 9 & 91 & 100.0 & 100.0 & \\
\hline For website & 9 & & 9.0 & & \\
\hline Valid Yes & & 72 & 72.0 & 79.1 & 79.1 \\
\hline No & & 19 & 19.0 & 20.9 & 100.0 \\
\hline Total & 9 & 91 & 100.0 & 100.0 & \\
\hline For EDI & 9 & & 9.0 & 100.0 & \\
\hline Valid Yes & & 30 & 30.0 & 33.0 & 33.0 \\
\hline No & & 61 & 61.0 & 67.0 & 100.0 \\
\hline Total & 9 & 91 & 100.0 & 100.0 & \\
\hline For phone & 9 & & 9 & & \\
\hline Valid Yes & & 6 & 6.0 & 6.6 & 6.6 \\
\hline No & & 85 & 85.0 & 93.4 & 100.0 \\
\hline Total & 9 & 91 & 100.0 & 100.0 & \\
\hline Virtual meeting & 9 & & 9.0 & & \\
\hline Valid Yes & & 10 & 10.0 & 11.0 & 11.0 \\
\hline No & & 81 & 81.0 & 89.0 & 100.0 \\
\hline Total & 9 & 91 & 100.0 & 100.0 & \\
\hline Other & 9 & & 9.0 & & \\
\hline Valid Yes & & 13 & 13.0 & 14.3 & 14.3 \\
\hline No & & 78 & 78 & 85.7 & 100.0 \\
\hline Total & 9 & 91 & 100.0 & 100.0 & \\
\hline N =91 & & & & \\
\hline & & & & \\
\hline
\end{tabular}


Table 8. Frequencies of respondent with websites

\begin{tabular}{|l|l|l|l|l|l|}
\hline Statement & Missing & Frequency & Percent & $\begin{array}{l}\text { Valid } \\
\text { percent }\end{array}$ & Cumulative\% \\
\hline $\begin{array}{l}\text { Respondent with } \\
\text { website }\end{array}$ & 1 & & 1.0 & & \\
\hline Valid Yes & & 71 & 71.1 & 71.7 & 71.7 \\
\hline No & & 28 & 28.0 & 28.3 & 100.0 \\
\hline Total & 1 & 99 & 100.0 & 100.0 & \\
\hline N=99 & \multicolumn{5}{l|}{} \\
\hline
\end{tabular}

Table 9. Frequencies of year of first website

\begin{tabular}{|l|l|l|l|l|l|}
\hline & Missing & Frequency & Percent & Valid percent & $\begin{array}{l}\text { Cumulative } \\
\text { percent }\end{array}$ \\
\hline & 32 & & 32.0 & & \\
\hline Valid & & & & & \\
\hline 1991 & & 2 & 2.0 & 2.9 & 2.9 \\
\hline 1994 & & 1 & 1.0 & 1.5 & 4.4 \\
\hline 1995 & & 5 & 5.0 & 7.4 & 11.8 \\
\hline 1996 & 3 & 3.0 & 4.4 & 16.2 \\
\hline 1997 & & 1 & 1.0 & 1.5 & 17.6 \\
\hline 1998 & & 4 & 4.0 & 5.9 & 23.5 \\
\hline 1999 & 10 & 10.0 & 14.7 & 38.2 \\
\hline 2000 & & 14 & 14.0 & 20.6 & 58.8 \\
\hline 2001 & 12 & 12.0 & 17.6 & 76.5 \\
\hline 2002 & & 7 & 7.0 & 10.3 & 86.8 \\
\hline 2003 & & 4 & 4.0 & 5.9 & 92.6 \\
\hline 2004 & & 3 & 3.0 & 4.4 & 97.1 \\
\hline 2005 & 2 & 2.0 & 2.9 & 100.0 \\
\hline & 68 & 100.0 & 100.0 & \\
\hline $\mathrm{N}=68$ & 32 & 68 & & \\
\hline
\end{tabular}

Table 10. Frequencies of year of start with internet

\begin{tabular}{|l|l|l|l|l|l|}
\hline & Missing & Frequency & Percent & Valid percent & $\begin{array}{l}\text { Cumulative } \\
\text { percent }\end{array}$ \\
\hline & 19 & & 19.0 & & \\
\hline Valid & & & & & \\
\hline 1986 & & 1 & 1.0 & 1.2 & 1.2 \\
\hline 1988 & & 1 & 1.0 & 1.2 & 2.5 \\
\hline 1990 & & 4 & 4.0 & 4.4 & 7.4 \\
\hline 1994 & & 2 & 2.0 & 2.5 & 9.9 \\
\hline 1995 & & 4 & 4.0 & 4.9 & 14.8 \\
\hline 1996 & & 8 & 8.0 & 9.9 & 24.7 \\
\hline 1997 & 6 & 6.8 & 7.4 & 32.1 \\
\hline 1998 & & 10 & 10.0 & 12.3 & 44.4 \\
\hline 1999 & 9 & 9.0 & 11.1 & 55.6 \\
\hline 2000 & 19 & 19.0 & 23.5 & 79.0 \\
\hline 2001 & & 7 & 7.0 & 8.6 & 87.7 \\
\hline 2002 & & 5 & 5.0 & 6.2 & 93.8 \\
\hline 2003 & & 3 & 3.2 & 3.7 & 97.5 \\
\hline 2004 & & 2 & 2.0 & 2.5 & 100.0 \\
\hline Total & 19 & 81 & 100.0 & 100.0 & \\
\hline $\mathrm{N}=81$ & & \multicolumn{5}{l}{} \\
\hline
\end{tabular}


Table 11. Frequencies of main initiator

\begin{tabular}{|l|l|l|l|l|l|}
\hline Statement & Missing & Frequency & Percent & $\begin{array}{l}\text { Valid } \\
\text { percent }\end{array}$ & Cumulative\% \\
\hline Main initiator & 14 & & 14.0 & & \\
\hline Valid Owner & & 53 & 53.0 & 61.6 & 61.6 \\
\hline Employee & & 12 & 12.0 & 14.0 & 75.6 \\
\hline Customer & & 9 & 9.0 & 10.5 & 86.0 \\
\hline Business partner & & 1 & 1.0 & 1.2 & 87.2 \\
\hline Other & & 7 & 7.0 & 8.1 & 95.3 \\
\hline $\begin{array}{l}\text { I am not sure/do not } \\
\text { know }\end{array}$ & 4 & 4.0 & 4.7 & 100.0 \\
\hline Total & 46 & 100.0 & 100.0 & \\
\hline $\mathrm{N}=86$ & 86 & & \\
\hline
\end{tabular}

Table 12. Descriptive statistics drivers of adoption

\begin{tabular}{|l|l|l|l|}
\hline Statement & $\mathrm{N}$ & Mean & Std. Deviation \\
\hline Customer demand & 90 & 3.19 & 1.521 \\
\hline Supplier pressure & 91 & 2.5 & 1.357 \\
\hline Competitive pressure & 91 & 2.76 & 1.456 \\
\hline Offered incentive & 91 & 1.7 & 1.080 \\
\hline Suited way of doing business & 91 & 3.86 & 1.17 \\
\hline Reduce administrative cost & 91 & 2.57 & 1.335 \\
\hline Reduce production & 91 & 2.11 & 1.251 \\
\hline Reduce distribution & 91 & 2.19 & 1.246 \\
\hline Reduce personal cost & 90 & 2.39 & 1.269 \\
\hline Reduce inventory cost & 91 & 1.88 & .987 \\
\hline Improve inventory management & 91 & 2.08 & 1.213 \\
\hline Improve customer service & 90 & 3.9 & 1.190 \\
\hline Marketing & 91 & 4.00 & 1.317 \\
\hline Reach new customer & 91 & 3.88 & 1.489 \\
\hline Increase revenue & 91 & 3.57 & 1.318 \\
\hline Improve competitiveness & 91 & 3.78 & 1.162 \\
\hline Reduce lead time & 91 & 2.59 & 1.491 \\
\hline Higher degree of control & 91 & 2.38 & 1.306 \\
\hline Improve operational efficiency & 90 & 3.00 & 1.438 \\
\hline Other comments & 90 & 4.29 & 1.463 \\
\hline Valid N ( list wise & 88 & & \\
\hline
\end{tabular}

Table 13. Descriptive statistics of difficulties

\begin{tabular}{|l|l|l|l|l|l|}
\hline Statement & $\mathrm{N}$ & Minimum $\mathrm{m}$ & Maximum $\mathrm{m}$ & Mean & Std. Deviation \\
\hline Change business process & 91 & 0 & 4 & 2.41 & 1.095 \\
\hline Obtain expertise & 90 & 0 & 5 & 2.82 & 1.379 \\
\hline Integrating existing systems & 90 & 0 & 5 & 2.46 & 1.210 \\
\hline Choose appropriate use & 90 & 0 & 5 & 2.72 & 1.298 \\
\hline Purchasing most appropriate & 90 & 0 & 5 & 2.74 & 1.329 \\
\hline $\begin{array}{l}\text { Obtaining employee } \\
\text { acceptance }\end{array}$ & 90 & 0 & 5 & 2.08 & 1.317 \\
\hline Customer technical issues & 90 & 0 & 5 & 2.31 & 1.504 \\
\hline Supplier technical issues & 90 & 0 & 5 & 1.82 & 1.295 \\
\hline Determining total cost & 90 & 0 & 5 & 2.52 & 1.463 \\
\hline Other comments & 90 & 0 & 5 & 4.47 & 1.201 \\
\hline
\end{tabular}


Table 14. Descriptive statistics of benefits

\begin{tabular}{|l|l|l|l|l|l|}
\hline Statement & $\mathrm{N}$ & Minimum m & Maximum m & Mean & Std. Deviation \\
\hline Reduce admin cost & 91 & 0 & 5 & 2.41 & 1.325 \\
\hline Reduce production cost & 91 & 0 & 5 & 2.09 & 1.279 \\
\hline Reduce distribution cost & 91 & 0 & 4 & 2.09 & 1.262 \\
\hline Reduce personal cost & 91 & 0 & 5 & 2.32 & 1.290 \\
\hline Reduce inventory cost & 91 & 0 & 5 & 1.89 & 1.233 \\
\hline Improved inventory mgm & 91 & 0 & 5 & 2.22 & 1.444 \\
\hline Improved customer service & 91 & 0 & 5 & 2.89 & 1.178 \\
\hline Improve marketing & 90 & 0 & 5 & 3.88 & 1.297 \\
\hline Increased customer base & 90 & 0 & 5 & 3.61 & 1.330 \\
\hline Increased revenue & 90 & 0 & 5 & 3.53 & 1.274 \\
\hline Improved competitiveness & 90 & 0 & 5 & 3.6 & 1.347 \\
\hline Reduce lead time & 90 & 0 & 5 & 2.59 & 1.586 \\
\hline $\begin{array}{l}\text { Higher degree of control } \\
\text { managing business }\end{array}$ & 90 & 0 & 5 & 2.46 & 1.4 \\
\hline $\begin{array}{l}\text { Improved operational } \\
\text { efficiency }\end{array}$ & 90 & 0 & 5 & 2.73 & 1.556 \\
\hline Other comments & 89 & 0 & 4 & 3.43 & 1.147 \\
\hline Valid N ( list wise ) & 89 & & & & \\
\hline
\end{tabular}

Table 15. Descriptive statistics of problems

\begin{tabular}{|l|l|l|l|l|l|}
\hline Statement amount of & $\mathrm{N}$ & Minimum $\mathrm{m}$ & Maximum $\mathrm{m}$ & Mean & Std. Deviation \\
\hline $\begin{array}{l}\text { Increased } \\
\text { resources spent IT }\end{array}$ & 0 & 5 & 3.18 & 1.427 \\
\hline Reduced flexibility & 90 & 0 & 4 & 2.03 & 0.827 \\
\hline Reduced IT security & 90 & 0 & 5 & 2.54 & 1.4 \\
\hline $\begin{array}{l}\text { Duplicated business process } \\
\text { Deteriorated }\end{array}$ & 90 & 0 & 4 & 2.11 & 1.075 \\
\hline $\begin{array}{l}\text { Relationships with customer } \\
\text { Deteriorated }\end{array}$ & 90 & 0 & 4 & 1.71 & 0.753 \\
\hline Relationships with suppliers & 90 & 0 & 4 & 1.66 & 0.823 \\
\hline Increased admin cost & 90 & 0 & 5 & 2.7 & 1.258 \\
\hline Increased production cost & 90 & 0 & 4 & 1.81 & 0.860 \\
\hline Increased distribution cost & 90 & 0 & 4 & 1.72 & 0.848 \\
\hline Increased personal cost & 90 & 0 & 5 & 2.04 & 1.088 \\
\hline Increased inventory cost & 90 & 0 & 4 & 1.79 & 0.855 \\
\hline $\begin{array}{l}\text { Reduced operational } \\
\text { efficiency }\end{array}$ & 89 & 0 & 4 & 1.98 & 0.988 \\
\hline Other comments & 90 & 0 & 3 & 2.79 & 0.609 \\
\hline Valid N ( list wise ) & 89 & & & & \\
\hline
\end{tabular}

Table 16. Single population proportion test

\begin{tabular}{|l|l|}
\hline Null hypothesis & $\mathrm{P} \geq 0.5(50 \%)$ \\
\hline Level of significance & 0.05 \\
\hline Sample size & 77 \\
\hline Sample proportion & 0.87 \\
\hline Z test statistics & 6.49 \\
\hline One tailed test & 1.65 \\
\hline Critical value & \multicolumn{2}{|l|}{} \\
\hline Reject the null hypothesis &
\end{tabular}


Table 17. Z test of hypothesis for the Mean

\begin{tabular}{|l|l|}
\hline Null hypothesis & $\mu \geq 6.5$ \\
\hline Level of significance & 0.05 \\
\hline Sample standard deviation & 2.347 \\
\hline Sample size & 77 \\
\hline Sample Mean & 5.17 \\
\hline Standard error of the Mean & 0.267465473 \\
\hline Z test statistics & -4.962604446 \\
\hline One tailed test & -1.65 \\
\hline Lower critical value & 1.65 \\
\hline Upper critical value & \\
\hline Reject the null hypothesis & \\
\hline
\end{tabular}

Table 18. Analysis of Variance ( ANOVA ), Hypothesis 3

\begin{tabular}{|l|l|}
\hline Null hypothesis & $\mu 1=\mu 2=\ldots . \mu 19$ \\
\hline Alternative hypothesis & The means are not equal \\
\hline Statistical Test & $\mathrm{F} ; \mathrm{P}$ value \\
\hline Calculated Value & $\mathrm{F}=49.99$, d.f $(18.1533) ; \mathrm{P}=0.000$ \\
\hline Significance Level & 0.05 \\
\hline Critical Test Level & $\mathrm{p}$ - value of zero \\
\hline Reject the null hypothesis
\end{tabular}

Table 19. Analysis of Variance ( ANOVA ), Hypothesis 4

\begin{tabular}{|l|l|}
\hline Null hypothesis & $\mu 1=\mu 2=\ldots \mu \mu$ \\
\hline Alternative hypothesis & The means are not equal \\
\hline Statistical Test & $\mathrm{F} ; \mathrm{P}$ value \\
\hline Calculated Value & $\mathrm{F}=4.7$, d.f $(8.697) ; \mathrm{P}=0.000$ \\
\hline Significance Level & 0.05 \\
\hline Critical Test Level & $\mathrm{p}$ - value of zero \\
\hline Reject the null hypothesis
\end{tabular}

Table 20. Analysis of Variance ( ANOVA ), Hypothesis 5

\begin{tabular}{|l|l|}
\hline Null hypothesis & $\mu 1=\mu 2=\ldots \mu \mu 14$ \\
\hline Alternative hypothesis & The means are not equal \\
\hline Statistical Test & $\mathrm{F} ; \mathrm{P}$ value \\
\hline Calculated Value & $\mathrm{F}=39.75$, d.f $(13.1089) ; \mathrm{P}=0.000$ \\
\hline Significance Level & 0.05 \\
\hline Critical Test Level & $\mathrm{p}$ - value of zero \\
\hline Reject the null hypothesis \\
\hline
\end{tabular}

Table 21. Analysis of Variance ( ANOVA ), Hypothesis 6

\begin{tabular}{|l|l|}
\hline Null hypothesis & $\mu 1=\mu 2=\ldots \mu 12$ \\
\hline Alternative hypothesis & The means are not equal \\
\hline Statistical Test & $\mathrm{F} ; \mathrm{P}$ value \\
\hline Calculated Value & $\mathrm{F}=34.54$, d.f $(11.959) ; \mathrm{P}=0.000$ \\
\hline Significance Level & 0.05 \\
\hline Critical Test Level & $\mathrm{p}$ - value of zero \\
\hline Reject the null hypothesis
\end{tabular}

